\title{
Blueberry thinning improved fruit quality and put forward maturation
}

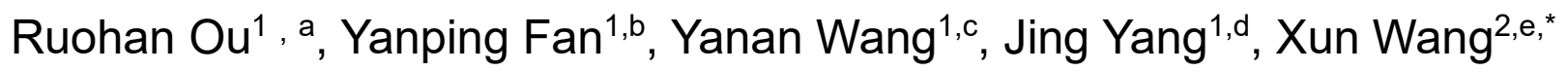 \\ 1: College of Horticulture, Sichuan Agricultural University, Chengdu, Sichuan, China \\ 2: Institute of Pomology \& Olericulture, Sichuan Agricultural University, Chengdu, Sichuan, China \\ a1974594047@qq.com,,b1379167867@qq.com, ${ }^{\text {c89 }}$ @431252@qq.com, ${ }^{\mathrm{d}} 769751475 @ q q . c o m,{ }^{3} 35744$ \\ 023@qq.com
}

*Corresponding author: wangxun0104@hotmail.com

Key words: blueberry; fruit thinning; fruit quality; fruit maturation.

Abstract: Using the three-year-old 'Britewell' blueberry as experiment material, this research studied the mature period of blueberry on different fruit thinning treatments $(20 \%, 40 \%$ and $60 \%$ thinning ratio per panicle). The fruit weight, size, firmness, soluble solids content, moisture content, anthocyanin content, ascorbic acid content and titratable acid content were determined. The result showed that asfruit thinning degree increasing, the single fruit weight, size and ascorbic acid content of blueberry increased. Soluble solids content of $60 \%$ thinning treatment fruits increased by $9.52 \%$ compared with that of control. Anthocyanin contents in fruit treated with $20 \%, 40 \%$ and $60 \%$ thinning degrees were increased by $17.13 \%, 2.29 \%$ and $20.18 \%$ respectively compared with that of control. Meanwhile, the maturity rate per panicle was significantly improved.

Blueberry is rich in nutrients, and is designated as one of the five healthy human foods ${ }^{[1-3]}$. There are some problems on fresh blueberry fruit production, such as the dispersed mature period, varying grain size and uneven coloring, which greatly affected the production efficiency of blueberries. Improving the quality of fruit has become one of the main objectives of blueberry research.

Fruit thinning is one of the important means to improve the quality of fruit, which could increase the fruit volume and fruit setting rate, promote coloring and maturity, reduce the rotting rate $^{[4]}$. Studies concerning fruit thinning has been reported on grape ${ }^{[5]}$ plum $^{[6]}$ and apple ${ }^{[7]}$, etc. However, there is limited study focusing on blueberry thinning ${ }^{[4]}$. In this experiment, 'Brightwell' blueberry was used as materials to study the effects of fruit thinning on fruit quality and maturity, which contributes to determine the optimal number of fruit thinning for blueberry cultivation. This study is aim to provide reference for the development of blueberry cultivation technology, explore a new way that panicle becomes the unit of blueberry picking and selling.

\section{Materials and methods}

\section{Blueberry materials}

The experiment was carried out in blueberry base of Chengdu, Pujiang. The material was three-year-old blueberry cv. 'Britewell'. The test panicles were listed and the fruit numbers were counted. Thinned the marked panicles before the fruits entered the enlargement period (About $30 \mathrm{~d}$ after anthesis). The diseases fruits, infested fruits and deformed fruits were thinned. The other managements were the same. The experiment set up 3 different thinning levels, 20\%, $40 \%$ and $60 \%$ per single panicle. The control is the fruit without thinning. Each treatment was repeated for 3 times. 


\section{Determination of fruit appearance qualities}

Each panicle was randomly selected for 30 representative fruits. Electronic balances $(0.01 \mathrm{~g})$ were used to determine single fruit weight. The vertical diameter and transverse diameter of each fruit were measured by vernier caliper. The firmness was measured by GY-1 fruit firmness tester.

\section{Determination of fruit intrinsic qualities}

Soluble solids content of fruit was measured by hand-held Sugar Meter. Titratable acid content was measured by acid-base titration. Ascorbic acid was measured by 2,6-dichlorophenol indophenol titration $^{[8]}$. Anthocyanin was extracted by acetone aqueous solution extraction and determined its content by UV spectrophotometry ${ }^{[9]}$.

\section{results and analysis}

\section{Effects of fruit thinning on blueberry appearance quality}

Fruit thinning has a significant effect on the size and weight of 'Britewell' blueberry (Table 1). Compared with the control, the fruit transverse diameter of $20 \%, 40 \%, 60 \%$ thinning treatment were increased by $10.94 \%, 6.72 \%$ and $16.40 \%$. The longitudinal diameter of $20 \%, 40 \%, 60 \%$ thinning treatment were increased by $10.34 \%, 4.69 \%$ and $15.46 \%$. The single fruit weight of $20 \%, 40 \%, 60 \%$ thinning treatment were increased by $34.93 \%, 21.92 \%$ and $57.53 \%$. Thus, fruit thinning could significantly improve the appearance quality of blueberry.

Table 1 Effects of fruit thinning on blueberry appearance quality

\begin{tabular}{llll}
\hline Treatments & $\begin{array}{l}\text { Single fruit } \\
\text { weight }(\mathrm{g})\end{array}$ & $\begin{array}{l}\text { Transverse } \\
\text { diameter }(\mathrm{mm})\end{array}$ & $\begin{array}{l}\text { Vertical diameter } \\
(\mathrm{mm})\end{array}$ \\
\hline Thinning 20\% & $1.97 \pm 0.026 \mathrm{ab}$ & $15.42 \pm 0.067 \mathrm{ab}$ & $12.70 \pm 0.418 \mathrm{ab}$ \\
Thinning 40\% & $1.78 \pm 0.276 \mathrm{ab}$ & $14.84 \pm 1.115 \mathrm{ab}$ & $12.05 \pm 0.789 \mathrm{ab}$ \\
Thinning 60\% & $2.30 \pm 0.490 \mathrm{c}$ & $16.18 \pm 1.174 \mathrm{c}$ & $13.29 \pm 1.000 \mathrm{c}$ \\
CK & $1.46 \pm 0.146 \mathrm{a}$ & $13.90 \pm 0.725 \mathrm{a}$ & $11.51 \pm 0.682 \mathrm{a}$ \\
\hline
\end{tabular}

The different lowercase letters behind the same data show significant difference at the 0.05 level, the same below.

\section{Effects of different fruit thinning ratios on fruit firmness and water content}

The fruit firmness of all thinning treatments showed lower levels than that of control. The fruits of $60 \%$ thinning treatment gained the lowest firmness $\left(1.13 \mathrm{~kg} / \mathrm{cm}^{2}\right)$, which was significantly lower than the control firmness. The effect of different fruit thinning treatments on blueberry water content is not significant $(P<0.05)$.

Table 2 Effects of fruit thinning on blueberry firmness and water content

\begin{tabular}{lll}
\hline Treatments & Firmness $\left(\mathrm{kg} / \mathrm{cm}^{2}\right)$ & Water content $(\%)$ \\
\hline Thinning $20 \%$ & $1.16 \pm 0.170 \mathrm{ab}$ & $80.42 \pm 0.600 \mathrm{a}$ \\
Thinning $40 \%$ & $1.23 \pm 0.040 \mathrm{a}$ & $79.37 \pm 0.726 \mathrm{a}$ \\
Thinning $60 \%$ & $1.13 \pm 0.107 \mathrm{c}$ & $80.63 \pm 0.519 \mathrm{a}$ \\
CK & $1.32 \pm 0.392 \mathrm{ab}$ & $79.45 \pm 0.317 \mathrm{a}$ \\
\hline
\end{tabular}

Effects of fruit thinning on the blueberry anthocyanin, ascorbic acid and titratable acid content

The soluble solids content of all thinning treatments were higher than that of control. The fruit 
soluble solids content of $60 \%$ thinning treatment was $9.52 \%$ higher than that of control, which indicates that the higher fruit thinning ratio leads to higher soluble sugar and organic acids content. The anthocyanin contents of all fruit thinning treatments were higher than that of control. The anthocyanin content increased by $17.13 \%, 2.29 \%$ and $20.18 \%$ after thinning $20 \%, 40 \%$ and $60 \%$ of fruits per panicle, respectively. The content of ascorbic acid increased with the increase of fruit thinning ratio. The fruit ascorbic acid content of $60 \%$ thinning treatment was the highest $(32.54$ $\mathrm{nmol} / \mathrm{g}$ ). Comparing with the control, the ascorbic acid contents in treatments of $20 \%, 40 \%$ and $60 \%$ thinning increased by $2.47 \%, 21.96 \%$ and $43.47 \%$ respectively. The effect of different thinning ratios on the blueberry titratable acid content was not obvious $(P<0.05)$.

Table 3 Effects of thinning on blueberry soluble solids, anthocyanin, ascorbic acid and titratable acid content

\begin{tabular}{lllll}
\hline Treatments & $\begin{array}{c}\text { Soluble solids } \\
(\%)\end{array}$ & $\begin{array}{l}\text { Anthocyanin } \\
(\mathrm{nmol} / \mathrm{g})\end{array}$ & $\begin{array}{l}\text { Ascorbic } \\
\text { acid(mg/100g) }\end{array}$ & Titratable acid(\%) \\
\hline Thinning 20\% & $14.6 \pm 0.351 \mathrm{ab}$ & $3387.25 \pm 0.544 \mathrm{c}$ & $23.24 \pm 1.040 \mathrm{ab}$ & $0.116 \pm 0.028 \mathrm{a}$ \\
Thinning 40\% & $14.8 \pm 0.200 \mathrm{ab}$ & $2958.05 \pm 1.399 \mathrm{ab}$ & $27.66 \pm 1.271 \mathrm{~b}$ & $0.103 \pm 0.026 \mathrm{a}$ \\
Thinning 60\% & $16.1 \pm 1.002 \mathrm{c}$ & $3475.44 \pm 0.707 \mathrm{c}$ & $32.54 \pm 1.074 \mathrm{c}$ & $0.108 \pm 0.023 \mathrm{a}$ \\
CK & $14.7 \pm 0.173 \mathrm{a}$ & $2891.76 \pm 1.355 \mathrm{a}$ & $22.68 \pm 0.614 \mathrm{a}$ & $0.117 \pm 0.013 \mathrm{a}$ \\
\hline
\end{tabular}

\section{Effects of thinning on blueberry maturity}

Fruit thinning greatly promoted the panicle maturity and shorten the mature period of fruit. A month after fruit thinning, the fruit mature rate of $20 \%, 40 \%$ and $60 \%$ thinning treatment were significantly increased by $63.05 \%, 57.35 \%$ and $76.91 \%$ compared with the control. Therefore, fruit thinning could promote the ripening of blueberry.

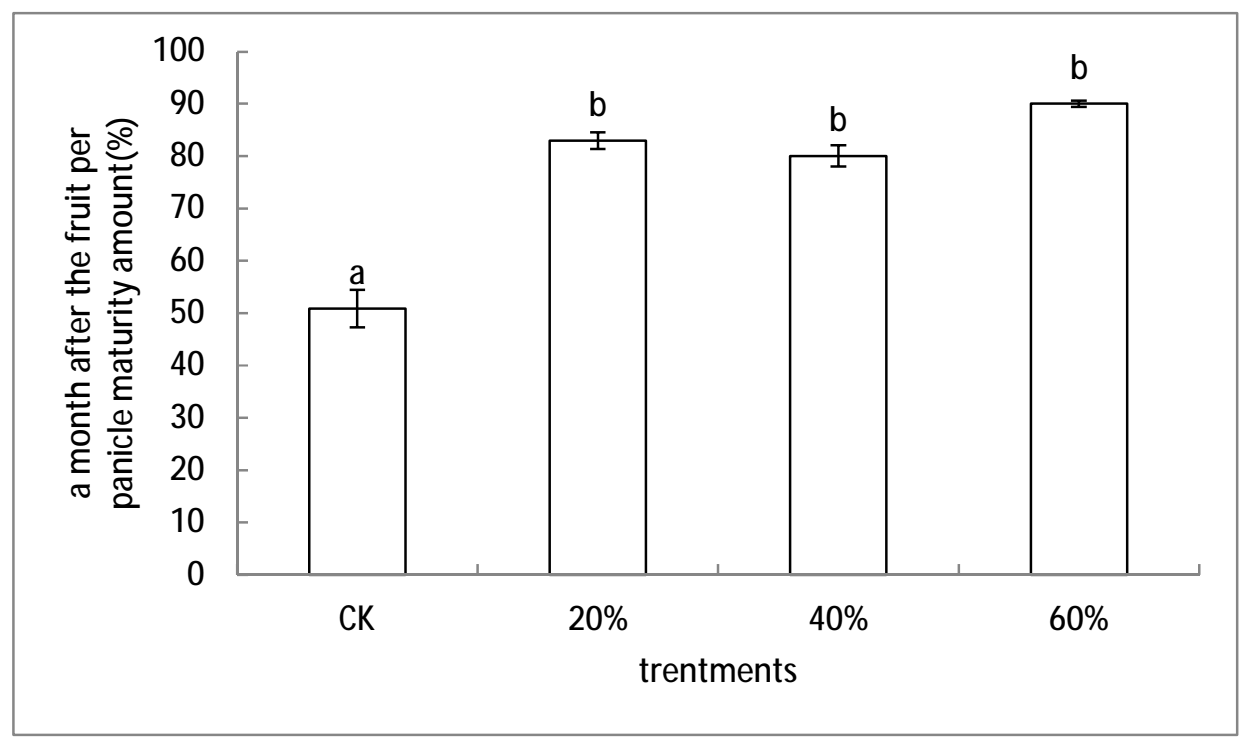

Figure 1 Effects of different thinning ratios on the blueberry mature rate

\section{Discussions}

The quality of fruit is affected by many factors and the load is one of the key factors. Thinning treatment reduces the number of fruit, which is beneficial to the accumulation of fruit nutrients, and to promote the rapid increase of cell volume. Fruit thinning is an effective measure to increase the fruit quality ${ }^{[10]}$, which is helpful to further improve the commodity value and quality of blueberry. Removing abnormal fruit, small fruit and infested fruit could improve the nutrition of panicle, the light transmittance ${ }^{[11]}$. 
The results showed that fruit thinning could significantly improve the appearance and internal quality, greatly improve the economic benefits of blueberry fruit. Fruit thinning could improve blueberry fruit weight and size. The anthocyanin content and ascorbic acid content of fruit thinning treatments were significantly higher than that of the control, and the fruit firmness of fruit thinning treatments was lower than that of control. Therefore, the blueberry fruit thinned tasted better. Reasonable fruit thinning could also promote the blueberry maturity, and to achieve the same maturity as possible on one panicle, which can be sold by panicle as unit. This sales model could reduce the cost of manual removal, reduce the loss caused by single picking, and improve economic efficiency.

\section{References}

[1]Yang LY. Nutritional health function and product development of blueberry. Chinese food and nutrition, 2007, 4:26-27.

[2] Gu Y. Determination of fruit nutrient of rabbit blueberry cultivars. Journal of plant resources and environment, 1998, 3:34-38.

[3]Zhu ZR. Study on tissue culture of Vaccinium rabbit blueberry. Guizhou forestry science and technology, 2003, 4:20-22.

[4]Zhao XE. Cultivation of blueberry blueberry.Anhui forestry, 2005, 6:32.

[5]Niu LX. Thinning flowers and fruit and grape quality. Northern horticulture, 1991,(09): 35-36.

[6]Zhou DR. Effects of fruit thinning on quality and vegetative growth of plum. Southeast horticulture, 2016, 4(2):1-6.

[7]Wang WX. Effects of different fruit thinning periods and fruit yield on fruit quality and flower bud differentiation. Liaoning fruit tree, 1982, 1:68-69.

[8]Cao JK. The guidance of postharvest physiology and biochemistry of fruits and vegetables. Beijing: China light industry press, 2007.

[9]Zhao ML. Extraction and detection of procyanidins from blueberry. Jiangxi chemical industry, 2014, 2:123-125.

[10]Wang Z. Plant physiology. Beijing: China agricultural press, 2000, 410-412.

[11]Wang J. The role of fruit thinning. Jilin agriculture, 2001,6:15. 